\title{
Choice of Malaria Care Services in Sissala West District in the Upper West Region of Ghana
}

\author{
Alhassan Tonsuglo \\ Bussie-Dafiama-Isaa District Assembly, Upper West Region, Ghana \\ Email:tonsuglu@yahoo.com \\ Peter B. Aglobitse \\ Department of Economics, University of Cape Coast, Ghana. \\ Email: paglobitse@gmail.com \\ and \\ Naasegnibe Kuunibe \\ Department of Economics and Entrepreneurship Development, \\ University for Development Studies, Ghana. \\ Email:edwardlatuo@yahoo.com \\ DOI: http://dx.doi.org/10.4314/gjds.v11i1.5
}

\begin{abstract}
Malaria poses a threat to the Ghanaian health system and a huge burden to the economy. In the Sissala West District, the trend of Out-Patients Department (OPD) attendance due to malaria keeps increasing even though the national figures show a decline. The study investigates malaria care provider choice in Sissala West District, using a multinomial logistic regression model. A cross-sectional survey design was used and data was collected from 400 malaria infected individuals or their caretakers in the district. The results showed that travel time and waiting time negatively influence the choice of all categories of malaria care providers in the district. Similarly, cost of treatment negatively influence self-medication and consultation at chemical store. The income level of respondents also influences self-medication and traditional medical practitioner while severity of infection influences the choice of chemical store and selfmedication. The study recommends the provision of more health facilities in the district, the intensification of public education on malaria prevention and control and the monitoring of the use of affordable anti-malaria drugs such as the Artemisinin based Combination Therapy (ACTs).
\end{abstract}

Key words: Choice, Multinomial Logit, Marginal Effects, Self-medication, Indirect Costs 


\section{Introduction}

Good health is vital to socio-economic development and is an important indicator of quality of life as well as a major contributor to human capital development. The Millennium Development Goals identify health as an integral part of the strategies of fighting poverty. Increased access to quality healthcare leads to reduction in poverty, a fact which explains why healthcare albeit expensive, constantly engages the attention of public authorities (Koudio, Monsan \& Gbongue, 2008).

Despite the critical role of health to development, malaria continues to pose a major public health threat to many countries the world over. The disease is caused by a parasite called Plasmodium, which is transmitted through the bites of infected female anopheles mosquitoes. The parasites multiply in the liver, and then infect red blood cells (Mendis, Sina, Marchesini, \& Carter, 2001). In the tropical and subtropical areas of the world the disease is widespread and threatens about 2.4 billion people or about 40 percent of the world's population who live in the world's poorest countries. In 2003 the World Health organization estimated that more than one million deaths are attributed to the disease annually; a leading cause of infant and child mortality in Sub-Saharan Africa and costs Africa over $\$ 12$ billion every year in lost domestic product.

In Ghana the disease is hyper-endemic and the entire population is at risk as it accounts for more than 44 percent of reported outpatient visits and an estimated 22 percent of under-five mortality in the country (Mendis et al., 2001).Through various donor agencies and seminars, there has been a concerted effort by the government and the Ghana Health Service to make the country a malaria-free state. These include the Roll Back Malaria Partnership programme which began in 1999 and adoption of the Global Strategy. The country became one of the 15 focused countries under the United States President's Malaria Initiative in 2007 (ibid).

Despite these efforts, achievements in fighting the disease have been minimal in the country as there has been some minimal decline in trends in Out-patient Department (OPD) for 2004 to 2007. In 2004 the OPD attendance which stood at 44.7, did not change in 2005, but reduced marginally to 38.7 in 2006 and reduced again to 33.15 in 2007 (National Malaria Control Programme, 2008). In spite of this the trend in the Sissala West District (SWD) has witnessed high and unstable figures even though the national OPD attendance has witnessed a decrease within the same period. In 2004 the OPD attendance stood at 41.9 percent, increasing dramatically to 62.3 percent in 2005 . The rate dropped to 52.4 percent and 44.2 in 2006 and 2007 respectively but increased again to 48.95 percent in 2008 (Sissala West District Assembly [SWDA], 2011). A better understanding of the factors influencing malaria care-seeking behaviour would assist policy makers to design appropriate public awareness programmes aimed at improving the situation in the district. The study therefore examines the factors that influence malaria care provider choice in Sissala West District. 


\section{Methodology}

\section{Study Design}

The study uses the cross-sectional survey design to examine the factors that influence malaria care provider choice in the SWD in the Upper West Region of Ghana. The unit of analysis is individuals who have been infected with malaria over the last three months. Any individual aged 20 years and above is considered old enough to represent the infected person in his/her physical absence. The malaria infected individuals or their representatives provided responses for all questions in the questionnaire.

The multistage sampling procedure was employed in this study. The Sissala West District has four (4) area councils. The first stage involved the selection of one community from each of the four (4) area councils. In order to arrive at the four communities, a list was generated for each area council. Using the simple random sampling technique, one community was selected from the list of communities for each of the area councils. The communities that were sampled included Silbelle (Pulima Area Council), Kunkorgu (Gwollu Area Council), Nyantie (Zini Area Council) and Wiiro (Fielmua Area Council).

Secondly, the proportionate sampling technique was used to allocate a quota to each community based on their respective population. Finally, the purposive sampling technique was employed to select a number of respondents from each community. Each community was screened to identify malaria cases where the questionnaires were administered. Table 1 shows the number of respondents from each community for the study. In all, 400 respondents were obtained.

Table 1: Distribution of respondents by community

\begin{tabular}{|l|l|l|}
\hline Community & Population & Sample \\
\hline Silbelle & 974 & 129 \\
\hline Kunkorgu & 803 & 106 \\
\hline Nyantie & 608 & 81 \\
\hline Wiiro & 633 & 84 \\
\hline Total & 2670 & 400 \\
\hline
\end{tabular}

Given the outcome variable (Choice of care provider) is a qualitative one, the following procedure proposed by Cochran (1977) for the determination of sample size for categorical data was use; where = the sample size, = the number relating to the degree of confidence anticipated in the result; in this case $95 \%$ confidence interval, = an estimate of the proportion of people falling into the group in which we are interested (people infected with malaria) and = proportion of error the researcher is prepared to accept (sampling error; $5 \%$ anticipated error). 
To get an estimate of the proportion (p) of people falling into the group, a pilot study of 40 respondents was conducted one month to the actual survey at a different community (Sorbelle), which has similar characteristics as the communities in the sample. Out of the 40 respondents who were infected with malaria, twenty-four (24) of them sought treatment from a facility. This gives $\mathrm{p}=0.60$ and $\mathrm{q}=1-\mathrm{p}=0.40$ and a sample size of 36 9 was arrived at. To take care of maximum error, the sample size of 369 was rounded up to 400 distributed according to the population of various communities included in the sample.

Data was collected using structured interview schedule developed based on the district profile and the set of study objectives. Questions were developed on each of the objectives. The collection of the data itself involved the help of two research assistants who were recruited and trained for the purpose.

\section{Analytical Framework}

This study derives its theoretical framework from the principles of utility maximization, based on the approach formulated by Mwabu, Ainsworth \& Nyamete (1993) modified by Odwee, Okurut, and Adebua (2006) and adopted (with modifications) by Kuunibe (2012). The utility maximizing individual, in the event of an illness, seeks help from a healthcare system characterized by many providers. The individual patient or his caretaker is further assumed to choose the healthcare alternative that yields the maximum expected utility. So that, conditional on seeking treatment, the direct utility derived by individual from treatment alternative can be expressed as:

$$
U_{i j}=u_{i j}\left(H_{i j}, C_{i j}\right)
$$

Where; is the direct conditional utility that individual expects from healthcare provider ; is the expected improvement in health status for individual after receiving treatment from provider, and is the consumption of non-healthcare goods, the amount of which depends on choice, because of the monetary and nonmonetary costs of treatment from provider . To facilitate empirical work, the unobservable variables, and can be expressed as in equations (2) and (3) respectively;

$$
H_{i j}=h\left(W_{i}, Q_{i j}\right)
$$

where is a vector of observable socio-economic attributes of individual such as age and education; is a vector of medical and physical attributes faced by individual in facility , such as availability of drugs and medical equipment and sanitary conditions of the facility; and ;

$$
C_{i j}=I_{i}-R_{i}
$$

where is the monetary value of non-healthcare goods that individual can consume after paying for medical care in facility, is annual income of respondent and is the value of 
resources that individual devotes to medical care received from facility $j$. The level of is observable and determined by such factors as the treatment fees, waiting time, and access variables such as distance and travel time, and can be expressed as;

$$
R_{i}=M_{i j}+w T_{i j}
$$

where is the total monetary cost of seeking treatment from health facility $j$ for individual $i$; is the travel time to health facility $j$ for individual $i$, including the time spent to wait for treatment there; and $w$ is the shadow wage rate. Notice that expressions (3) and (4) are merely accounting identities, which permit identification of; a variable for which information is normally not collected in healthcare demand surveys.

Equations (1) to (4) represent a general structural specification of a behavioural model of healthcare demand. The next stage is the choice of the functional form for the utility function in equation (1). Ideally a mathematical form for the utility function that is consistent both with actual demand behaviour and with rules of rational choice is necessary. Given that the utility function in equation (1) is linear in health status and quadratic in consumption, it is consistent with well-ordered preferences. Such a functional form generates typically observed demand patterns.

What is of interest in these specifications is the variation in monetary or time prices across healthcare providers that ensure identification of behavioural parameters; so that given this role of prices, and a further assumption that consumer preferences over the entire range of consumption goods are well defined, empirical healthcare demands can be shown to be consistent with the assumption that ill individuals maximize an indirect conditional utility function, as shown in equation (5);

$$
V_{i j}=v_{i j}\left(W_{i}, Q_{i}, I_{i}, P_{i j}, a_{i}\right)
$$

where and, are as previously defined; is the price of healthcare received by individual from health facility $j$; is the price of non-healthcare goods consumed by individual The general functional form for the indirect utility function in (5) contains three important features. First, by solving (5) one gets healthcare consumption bundles, rather than health status improvements or health outcomes. Second, consumption of non-health goods and services is constant for different levels of medical services. The constancy is achieved by assuming that the direct utility function that underlies (5) is separable in medical care goods and other consumption bundles. Third, apart from other prices, the indirect utility function in (5) is dependent on "medical care" prices and not on prices of "improvements in health status".

However, the undesirable feature of equation (5) is that, in the underlying direct utility function, people's welfare depends on medical care services, rather than on health outcomes. This disadvantage is mitigated by the fact that in the event of illness, people restore health status by consuming medical care services. Thus equation (5) permits an investigation of direct demand effects of prices and incomes and is the standard 
expression for the indirect utility function in consumer demand theory (Mwabu et al, 1993).

In the present context, it shows the maximum utility that individual can achieve, conditional on seeking treatment for an illness, controlling for income, healthcare prices, prices of other goodspersonal attributes, and facility specific characteristics. To ease econometric work, is normalized to unity. Notice further that all the elements of the indirect conditional utility function in equation (5) are directly observable and are the variables of interest to policymakers. Econometric implementation of the model requires the standard assumption that the utility function in equation (5) is stochastic, and is of the form:

$$
V_{i j}=v_{i j}^{*}+\mu_{i}
$$

where $v_{i j}^{*}$ the systematic component of utility and $\mu_{i}$ is an additive disturbance term.

Assuming that is normally distributed, equation (6) leads to a multinomial logit specification of individual choice of medical treatments and the probability that individual will seek treatment from health facility or use a particular treatment option, can be expressed as:

$$
F\left(H_{i j}\right)=\frac{\mu_{i}^{V_{i j}^{*}}}{\sum \mu_{i}^{V_{i j}^{*}}}
$$

which is the multinomial specification where, is the probability that individual will seek healthcare from provider is healthcare provider alternatives or treatment options from which individual $i$ can seek treatment for $j=1 \ldots . . . . j=5$ and include $1=$ self-care or selfmedication, $2=$ hospital, $3=$ traditional medical practitioner, $4=$ Community-based Health Planning and Services Compound (CHPS), $5=$ chemical store $\mu_{i}$; and $v_{i j}^{*}$ are as previously defined. But $v_{i j \text { can be expressed as }}^{*}$

$$
V_{i j}^{*}=\beta W_{i}+\emptyset Q_{j}+\delta P_{i j}
$$

In which case (7) becomes:

$$
F\left(H_{i j}\right)=\frac{\mu_{i}^{\beta W_{i}+\varnothing Q_{j}+\delta P_{i j}}}{\sum \mu_{i}^{\beta W_{i}+\varnothing Q_{j}+\delta P_{i j}}}
$$

Where, $F\left(H_{i j}\right), H_{i j}$ and are as previously defined; $\beta, \varnothing$ and $\delta$ are vectors of coefficients of $W_{i}, Q_{j}$ and $P_{i j}$ respectively. 


\section{Estimation Technique}

The estimation of equation (9) can be done using the log likelihood function. The loglikelihood function that needs to be maximized in order to estimate values of the parameter vectors; $\beta, \emptyset$ and $\delta$ is simply:

$$
L=\sum_{i} \sum_{j} G_{i j} \log \rho_{i j}
$$

Where L is the logarithm of the likelihood function ; $G_{i j}=1$ if individual $i$ chose health facility/treatment option $j$; otherwise $G_{i j}$ takes a value of zero. The estimated values for; $\beta$, $\emptyset$ and $\delta$ show the marginal effects of social and provider characteristics on conditional utility from a medical care provision alternative, as shown for example, in equation (7). Expression (9) can be used to estimate multinomial logit.

The above general model of utility maximization using a random utility model based on McFadden (1973) can be applied using the basic multinomial logit model expressed as:

$$
P_{r}(y=j)=\frac{e^{x \beta(j)}}{e^{x \beta(1)}+\cdots+e^{x \beta(j)}+e^{x \beta(J)}}(11)
$$

In order to achieve identification, we modify the equation by setting one of the coefficients to zero (Lindelow, 2002). Here the self-care option is the one set to zero; hence it is the reference healthcare option. All the variables in the modified models are relative variables; they permit estimation of the effects of care options relative to self-care. The modification enables us to interpret our results relative to a reference group. In terms of utility, they denote the extra utility gained by using specific facilities above that of selfcare.

The specific equation used to estimate the determinants in the choice of malaria treatment is given as:

$$
M T_{i j}=\frac{e_{i}^{\beta_{1} I N C+\beta_{2} E F+\beta_{3} A G+\beta_{4} S X+\beta_{5} E D U+\beta_{6} T F+\beta_{7} F I+\beta_{8} S I+\beta_{9} T C+\beta_{10} W T}}{\sum e_{i}^{\beta_{1} I N C+\beta_{2} E F+\beta_{3} A G+\beta_{4} S X+\beta_{5} E D U+\beta_{6} T F+\beta_{7} F I+\beta_{8} S I+\beta_{9} T C+\beta_{10} W T}} \text { (12) }
$$

Where $M T_{i j}$ refers to the treatment options of care available to an individual infected with malaria; self-care, hospital, traditional medical practitioner, Community-based Health Planning and Services (CHPS) compound and, Chemical store; INC represents annual income of respondent expressed in Ghana cedis (for those in the informal sector it is the value of their crops and/or animals at market price at the time of data collection), AG is age of respondent, SX is sex of respondent, EF is the perception of respondents about the effectiveness of malaria treatment, EDU is represents the highest level of education (in years) achieved by an individual, TF is time taken in minutes to the facility, FI is frequency of illness, SI is severity of illness (proxy for being able to attend work/school, or not being able to attend work/school due to malaria infection), TC is the amount paid (in Ghana 
cedis) for treatment at the facility visited and WT is time taken (in minutes) at the facility visited.

Estimation of equation (12) requires the use of numerical methods to find values of parameter vectors that maximize the likelihood (the log-likelihood) of observing the sample data. It is assumed that the healthcare providers/ treatment options form a set of mutually exclusive choices. Each sample respondent is a random and independent draw from the universe of respondents. Thus, the logarithm of the likelihood function, $L i$, for the observable sample of respondents, $N$, is given by

$$
\ln L_{i}=\sum_{i=1}^{N} \sum_{j=1}^{J} D_{i j} \ln P_{i j}
$$

Where $D_{i j}$ is a dichotomous variable that takes on the value unity if the respondent chooses alternative and zero otherwise. The interpretation of the estimated coefficients is complicated by the fact that the model is nonlinear in the explanatory variables. This means that the effect of independent variables on the probability of seeking a particular type of care will depend on the value of that and other independent variables. For this reason, results are best interpreted through the analysis of marginal effects.

\section{Discussion of Results}

\section{Descriptive Statistics}

The results in Table 2 indicate that 199 (49.75\%) of the respondents were males while 201 (50.25\%) were females. A great number of the respondents 183 (45.75\%) had no formal education, 128 (32\%) had at least primary education and 57 (14.25\%) attended Junior Secondary School or Middle School. The rest, 32 (8\%) had secondary or higher education. In terms of health insurance registration, 301 (75.25\%) had valid health insurance cards while $99(24.75 \%)$ had no valid health insurance cards.

In terms of the facility visited/ treatment option used, 162 (40.50\%) visited the hospital, $76(19 \%)$ consulted at the CHPS compound and 89 (22.25\%) went to the chemical store. Out of the rest, $66(16.50 \%)$ treated themselves while 7 (1.75\%) visited a traditional medical practitioner. The results also indicate that 72.25 percent of the respondents used less than thirty minutes to travel to the facility and 21 percent spent between thirty (30) to sixty (6o) minutes. A relatively smaller proportion (6.25\%) used more than sixty (6o) minutes.

Table 2: Descriptive statistics

\begin{tabular}{|l|l|l|}
\hline Variable & Frequency & Percentage \\
\hline
\end{tabular}




\begin{tabular}{|c|c|c|}
\hline \multicolumn{3}{|l|}{ Sex } \\
\hline Male & 199 & 49.75 \\
\hline Female & 201 & 50.25 \\
\hline \multicolumn{3}{|l|}{ Level of education } \\
\hline No education & 183 & 45.75 \\
\hline Primary education & 128 & 32 \\
\hline JSS/Middle school & 57 & 14.25 \\
\hline SSS/Tech/Voc/Higher & 32 & 8 \\
\hline \multicolumn{3}{|c|}{ Ownership of health insurance } \\
\hline No & 99 & 24.75 \\
\hline Yes & 301 & 75.25 \\
\hline \multicolumn{3}{|l|}{ Facility visited } \\
\hline Hospital & 162 & 40.50 \\
\hline CHPS Compound & 76 & 19 \\
\hline Chemical store & 89 & 22.25 \\
\hline Self care & 66 & 16.50 \\
\hline $\begin{array}{l}\text { Traditional medical } \\
\text { practitioner }\end{array}$ & 7 & 1.75 \\
\hline \multicolumn{3}{|l|}{ Travel time } \\
\hline Less than 30 minutes & 289 & 72.25 \\
\hline Between 30 to 60 minutes & 84 & 21 \\
\hline More than 60 minutes & 27 & 6.75 \\
\hline
\end{tabular}

Source: Field data, 2011

Table 3 presents the mean age of the respondents as approximately 25 years with a standard deviation of 17.81 . The mean annual income of $\mathrm{GH} \$ 170.88$ and standard deviation of $\mathrm{GH} \$ 192.50$ with a minimum income of $\mathrm{GH} \$ 2.50$ and maximum of $\mathrm{GH} \$ 1,100.00$ seems to represent a high typical score and wide spread of income among the respondents. Similarly, a mean waiting time of 104.04 and standard deviation of 144.16 given five minutes minimum and 540 minutes maximum waiting time suggest higher average and 
spread. Cost of treatment has a relatively smaller mean (1.89) and standard deviation (5.44).

Table 3: Summary statistics

\begin{tabular}{|l|l|l|l|l|}
\hline Variable & Mean & Std. Dev & Min & Max \\
\hline Age (complete years) & 24.70 & 17.81 & 18 & 78 \\
\hline Waiting time (minutes) & 104.04 & 144.16 & 5 & 540 \\
\hline Treatment cost (GHథ) & 1.89 & 5.44 & 0 & 50 \\
\hline Income (GHథ) & 170.88 & 192.5 & 2.5 & 1,100 \\
\hline
\end{tabular}

Source: Field data, 2011

\section{Determinants of Choice of Malaria Care Services}

The multinomial logistic regression model specified in equation (5) was used to estimate the probability of a malaria infected individual choosing a given care provider/treatment option. Self-care was selected as the base outcome because that is what is readily available to everybody. However, coefficient estimates obtained from a discrete choice model do not provide much meaningful interpretation by themselves. Therefore, the estimated parameters are transformed into marginal effects. The computed marginal effects will give us the magnitude of the change in the probability of visiting a particular provider or using a particular treatment option when the explanatory variable increases by 1 unit. Detailed discussion of the marginal effects of each case-specific variable on the probability of choosing each provider choice or treatment option is given below.

Table 4: Model results

\begin{tabular}{|c|c|c|c|c|c|c|c|c|c|}
\hline \multirow[t]{2}{*}{ Variable } & \multicolumn{2}{|c|}{ Hospital } & \multicolumn{2}{|c|}{ CHPS Compound } & \multicolumn{2}{|c|}{ Chemical } & \multicolumn{2}{|c|}{ Traditionalist } & \multirow{2}{*}{$\begin{array}{l}\text { Self-care } \\
\begin{array}{l}\text { Marginal } \\
\text { effects }\end{array}\end{array}$} \\
\hline & Coef & $\begin{array}{l}\text { Marginal } \\
\text { effects. }\end{array}$ & Coef & $\begin{array}{l}\text { Marginal } \\
\text { effects. }\end{array}$ & Coef & $\begin{array}{l}\text { Marginal } \\
\text { effects. }\end{array}$ & Coef & $\begin{array}{l}\text { Marginal } \\
\text { effects. }\end{array}$ & \\
\hline Age & -0.020 & -0.000 & -0.019 & 0.00 & -0.008 & 0.00 & -0.015 & $0.00^{*_{1}}$ & 0.000 \\
\hline Sex & $-1.569^{* *}$ & 0.106 & $-1.09^{* *}$ & -0.106 & $-1.184^{* *}$ & -0.00 & $-1.430^{* *}$ & 0.00 & $-0.000^{* *}$ \\
\hline 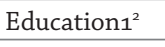 & -0.230 & 0.068 & -0.551 & -0.070 & -0.647 & -0.00 & 1.001 & 0.002 & 0.000 \\
\hline Education $^{3}$ & $0.003^{* * *}$ & 0.045 & $0.198^{* *}$ & 0.043 & -0.280 & -0.00 & 1.190 & 0.002 & 0.000 \\
\hline Education $3^{4}$ & $-1.222^{*}$ & 0.123 & $0.624^{*}$ & -0.123 & 0.701 & -0.00 & 1.588 & 0.001 & -0.000 \\
\hline $\begin{array}{l}\text { Frequency of } \\
\text { illness } 2^{5}\end{array}$ & $-0.312^{* *}$ & -0.092 & $0.102^{* *}$ & 0.093 & $-0.013^{*}$ & 0.00 & -1.552 & -0.002 & 0.000 \\
\hline $\begin{array}{l}\text { Frequency of } \\
\text { illness } 3^{6}\end{array}$ & $0.080^{* *}$ & -0.117 & 0.584 & 0.117 & $-0.239^{* *}$ & -0.00 & 0.506 & -0.00 & 0.000 \\
\hline $\begin{array}{l}\text { Severity of } \\
\text { infection }\end{array}$ & -0.398 & -0.045 & $-0.202^{*}$ & 0.043 & $0.433^{* *}$ & $-0.00^{*}$ & 0.024 & 0.00 & $0.000^{* *}$ \\
\hline
\end{tabular}




\begin{tabular}{|l|l|l|l|l|l|l|l|l|l|}
\hline Travel time2 $^{7}$ & $-1.53^{*}$ & $-0.124^{*}$ & $-0.941^{* *}$ & -0.122 & -0.112 & $-0.00^{* * *}$ & $-0.483^{* *}$ & $-0.007^{* *}$ & $-0.000^{*}$ \\
\hline Travel time3 & $-2.425^{* *}$ & $-0.229^{*}$ & $-1.068^{*}$ & $-0.173^{* *}$ & $-0.738^{* * *}$ & $-0.00^{* * *}$ & $-2.951^{* * *}$ & -0.001 & $-0.000^{* *}$ \\
\hline Waiting time & $-18.64^{* * *}$ & $-0.583^{* * *}$ & $-16.08^{* * *}$ & $-0.58^{* * *}$ & $-0.684^{* * *}$ & $-0.022^{* * *}$ & $-18.37^{* * *}$ & 0.001 & $0.003^{* *}$ \\
\hline $\begin{array}{l}\text { Effectiveness } \\
\text { of treatment }\end{array}$ & 3.226 & 0.317 & 1.820 & $-0.337^{*}$ & 2.144 & -0.00 & $19.66^{* * *}$ & $0.022^{* * *}$ & $0.001^{* *}$ \\
\hline $\begin{array}{l}\text { Cost of } \\
\text { treatment }\end{array}$ & -3.398 & -0.159 & $-2.676^{* *}$ & -0.160 & $-3.975^{* *}$ & $-0.00^{* * *}$ & $-3.755^{* *}$ & 0.00 & $-0.001^{* * *}$ \\
\hline $\begin{array}{l}\text { Annual } \\
\text { Income }\end{array}$ & 0.008 & 0.000 & 0.008 & 0.000 & 0.008 & -0.00 & 0.001 & $-0.00^{* *}$ & $0.000^{* * *}$ \\
\hline
\end{tabular}

Source: Field data, 2011

The results of Table 4 show that higher age tends to have a positive effect, though in very negligible proportion, on the probability of seeking care from a traditional medical practitioner. Thus, an additional year increases the probability of a malaria care seeker visiting the traditional medical practitioner by 0.00 percent at 10 percent level of significance. This is because as people age, health deteriorates and more health is needed as one ages to maintain one's basic health. In their study Aryeetey and Kanbur (2008) found that elderly people tend to favour self-medication rather than consult a medical assistant or nurse.

With regard to sex, males have the tendency to seek external care (healthcare apart from self-medication) compared to females. However, the significance of this relationship is only confirmed for the self-care option where males have a higher probability of seeking treatment for malaria from an external healthcare provider compared to females. Thus, the probability of males compared to females opting for self-medication reduces by 0.03 percent at 5 percent level of significance.

The likely explanations for this state of affairs lies in the fact that in rural communities such as those in the SWD, females tend to have less access to economic and social assets including means of transport compared to their male counterparts. This lack of access generally affects their ability to travel to health centres, especially when these centres are located outside their communities. In addition, the observation by Dzator and Asafu-Adjaye (2004) that decisions to obtain medical care is largely determined by men, could also explain the situation in the current studies. It is also worth noting that time constraint and lack of opportunity have often deterred women from seeking adequate care (Buor, 2004) and men are generally less constrained by distance and price than women when it comes to seeking health care Mwabu et al. (1993).

This situation must be a matter of serious concern to all stakeholders and health policy makers in the district because unlike men, the health needs of women are usually different and sometimes complex arising sometimes from natural factors like child bearing and care, which on many occasions requires them to seek medical treatment for the sake of their children, born or yet to born. 
Education above the basic level (primary) has a significant influence on the choice of malaria care provider/treatment option. Junior High/ Middle School leavers prefer to use either the hospital or CHPS compound. However secondary school leavers and beyond are less likely to seek care from the hospital but more likely to visit the CHPS compound. It implies that educated people generally seek care from orthodox sources than uneducated persons. This is because education affects peoples' beliefs and perceptions about social values including those of sickness and healing. Indeed, similar results were found in a study by Aryeetey and Kanbur (2008) (Eds) which indicated that educated people have preference for orthodox health care but seem indifferent between traditional practitioners and self-medication.

The severity of malaria infection has a negative effect on the choice of a chemical store but a positive effect on self-medication. If the severity of malaria illness changes from mild to acute malaria, the probability of a malaria care seeker opting for self-care increases by 0.05 percent at 5 percent level of significance whereas the probability of visiting a chemical store reduces by 0.1 percent at 10 percent level of significance. This is attributable to the unavailability of orthodox health facilities in these communities. In such situations it sounds logical to resort to traditional means or self-medication even if one is not sure of the quality. Oberlander and Elverdan (2000) and Osoro (2004) explained that quality of malaria treatment and severity of infection are significant in the choice of malaria care providers in Tanzania. This explanation implies that even though quality is important, any available treatment option might be used once illness becomes severe.

The marginal effect of travel time is confirmed for most of the categories healthcare providers in the district and it possesses the right (negative) sign. For care seekers who travel between 30 minutes and one hour, the probability of visiting hospital decreases by 12.4 percent at 10 percent level of significance while that of self-medication decreases by 0.02 percent at 10 percent level of significance. Similarly, the probability of visiting chemical store decreases by o.1 percent at 1 percent level of significance.

By these findings, people in the SWD can adequately meet their health care needs only when it is possible for them to access health facilities at relatively shorter time than they currently do. For this to happen however, there is the need for the construction of more health facilities in many communities in the district and to improve upon the road network so that even if people have to travel to other communities to seek care they could do so within the shortest possible time.

For those who travel more than an hour to access care for malaria treatment, the probability of visiting a hospital and a CHPS compound decrease by 22.9 percent and 17.3 percent respectively at the conventional 5 percent level of significance. In the same vein, the probability of visiting a chemical store decreases by 0.1 percent at 1 percent level of significance while that of self-medication reduces by 0.02 percent at 5 percent level of significance. This finding is comparable to the conclusion by Dzator et.al, (2004) and Kuunibe (2012) among others. 
Waiting time also has a negative effect and it is the most influential variable in determining the choice of malaria care providers in the district. At 1 percent level of significance, the probability of visiting a hospital for malaria care reduces by 58.3 percent given an additional hour of waiting time. Similarly, the probability of visiting a CHPS compound and chemical store reduces by 55.8 percent and 2.2 percent respectively at 1 percent level of significance. On the contrary, the probability of self-medication increases by 0.3 percent at 5 percent level of significance. The negative effect of travel and waiting time on the probability of choosing the orthodox healthcare providers seems to mirror poor accessibility of healthcare services in the district. As contained in the District Medium Term Development Plan (2007), over the years, access to health service has been low due to far distances between communities as well as poor road network in the district and limited number of facilities.

The perception of a malaria care seeker about the effectiveness of treatment has a negative effect on the choice of a CHPS compound but a positive effect on traditional medical practitioner and self-medication. For people who perceive treatment to be effective, the probability of visiting a CHPS compound reduces by 33.7 percent at 10 percent level of significance. On the contrary, the probability of visiting a traditional medical practitioner increases by 2.2 percent at 1 percent level of significance while that of self-medication increases by 0.1 percent at 5 percent level of significance.

Cost of treatment is significant and negative in the choice of chemical store and selfmedication. At 1 percent level of significance, the probability of visiting a chemical store and of self-medication each reduces by 0.1 percent. This finding is consistent with the results of de Bartolomeand Vosti (1995), Gertler, Locay, and Sanderson, (1987), Dorand van der Gaag (1988), and Dzator et al. (1994). A possible explanation for this finding is that about 25 percent of the sample population who are not covered by health insurance still pay cash for healthcare services, which discourages them from seeking care, especially from options such as the chemical store self-medication where both the quality of treatment and the outcome are not certain.

Income of a care seeker has a negative effect on the choice of traditional medical practitioner and positive effect on self-medication. A GH $\$ 1$ rise in income decreases the probability of a malaria care seeker visiting a traditional medical practitioner by 0.002 percent but increases the probability of self-medication by 0.006 percent at the conventional 5 percent level of significance. This conclusion agrees with the views expressed by Acton (1975) that non monetary factors assume an increasingly important role in determining the allocation of demand for medical care as out-of-pocket payment falls due to health insurance. This is evident from the fact that 75.25 percent of the population in the district had valid national health insurance cards. 


\section{Conclusion}

The study concludes that time prices (travel and waiting time) play an important role in determining the allocation of demand for medical care as out-of-pocket payment falls due to health insurance. This is evident from the fact that 75.25 percent of the population in the Sissala West District had valid National Health Insurance cards. The negative effect of these non-monetary factors on the consumption of malaria care is principally due to poor accessibility of healthcare services in the district; a situation aggravated by poor road network and limited number of health facilities as contained in the SWD Medium Term Development Plan for 2007.

The study further concludes that even though treatment cost is not significant in the choice of hospital for malaria treatment, it is highly significant in determining the probability of visiting other care providers. The findings show that about 25 percent of the populations who are not covered by health insurance still pay cash for healthcare services.

The analysis revealed that females are more inclined to self-medication. This is attributable to the fact that men have access to means of transport than women and this puts them at a disadvantage when it comes to accessing health care services at centres located outside their communities.

In order to reduce the effect of time prices and improve access, policy should target the provision of more health facilities. The participation and regulation of the private sector should be promoted in the provision of health facilities in the district. Public education on malaria prevention and control should be intensified coupled with the monitoring of the use affordable anti-malaria drugs such as the ACTs.

\section{References}

Acton, J. (1975). Non-monetary factors in the demand for medical services: Some empirical evidence. Journal of Political Economy, 87(3), pp 595-614.

Aryeetey, E. and Kanbur, R. (Eds). (2008). The economy of Ghana; Analytical perspectives on stability, growth \& poverty, Accra Newtown: James Currey Woeli Publishing Services.

Cochran, W, G, (1977).Sampling techniques (3rd ed). New York. John Wiley and Sons.

deBartolome, C., and Vosti, S. (1995). Choosing between public and private healthcare: A case study of malaria treatment in Brazil. Journal of Health Economics, (14), pp 191-205.

Dor, A., and van der Gaag, J. (1988). The demand for medical care in developing countries: Quantity rationing in rural Cote d'Ivoire. LSMS Working Paper 35 , World Bank. 
Dzator, J., and Asafu-Adjaye, J. (2004). A study of malaria care provider choice in Ghana.

Health Policy, 69(3), pp 389-401.

Gertler, P., Locay, L., and Sanderson, W. (1987). Are user fees regressive? The welfare implications of healthcare financing proposals in Peru. Journal of Econometrics, (36) pp. 67-88.

Kouadio, A., Monsan, V. and Gbongue, M. (2008). Social Welfare and Demand for Healthcare in the Urban Areas of Côte d'Ivoire. Africa Economic Research Consortium (AERC) Research Paper 181, Nairobi, Kenya.

Kuunibe, N. (2012). Choice of healthcare providers by households in Ghana; The case of Upper West Region. Germany: Lambert Academic Publishing.

Lindelow, M. (2002). Healthcare demand in rural Mozambique: Evidence from the 1996/97 household survey. International Food Policy Research Institute (IFPRI), FCND Discussion Paper, No. 126.

Mendis K, Sina B.J, Marchesini P, Carter R. (2001) The neglected burden of Plasmodium vivax malaria. The American Journal of Tropical Medicine and Hygine, 64(1-2 Suppl), pp 97-106.

McFadden, D. (1973). Conditional logit analysis of qualitative choice behaviour. New York: Academic Press.

Mwabu, G., Ainsworth, M., and Nyamete, A. (1993).Quality of medical care and choice of medical treatment in Kenya. The Journal of Human Resources, 28(4), 838-862.

Oberlander, L., and Elverdan, B. (2000). Malaria in United Republic of Tanzania: Cultural considerations and health-seeking behaviour. Bulletin of the World Health Organization, 78 (11), 1352-1357.

Odwee, J. J. A.O., Okurut, F. N., and Adebua, A. (2006). The determinants of healthcare demand in Uganda: The case study of Lira District, Northern Uganda. African Economic Research Consortium (AERC), Research Paper, 155, Nairobi, Kenya.

Osoro, 0. (2004). Determinants of healthcare demand for malaria treatment in Tabora District, Tanzania (Unpublished Master's thesis). University of Dar es Salaam, Dar es Salaam, Tanzania. 